\title{
Efficacy of short term versus long term tube thoracostomy drainage before tetracycline pleurodesis in the treatment of malignant pleural effusions
}

Andrew G Villanueva, Anthony W Gray Jr, David M Shahian, Warren A Williamson, John F Beamis Jr

\begin{abstract}
Background - A study was undertaken to compare the efficacy of short term tube thoracostomy drainage with standard tube thoracostomy drainage before instillation of tetracycline for sclerotherapy of malignant pleural effusions. Methods - The study consisted of a randomised clinical trial in a sequential sample of 25 patients with malignant pleural effusions documented cytopathologically. Fifteen patients were randomly assigned to group 1 (standard protocol) and 10 to group 2 (short term protocol). Patients in group 1 had tube thoracostomy suction drainage until radiological evidence of lung re-expansion was obtained and the amount of fluid drained was $<150 \mathrm{ml} /$ day, before tetracycline $(1.5 \mathrm{~g})$ was instilled. The chest tube was removed when the amount of fluid drained after instillation was $<150 \mathrm{ml} / \mathrm{day}$. Patients in group 2 also had suction drainage, but the tetracycline $(1.5 \mathrm{~g})$ was instilled when the chest radiograph showed the lung to be re-expanded and the effusion drained, which was usually within 24 hours. The chest tube was removed the next day.

Results - The response to tetracycline sclerotherapy in the two groups was the same $(80 \%)$ but the duration of chest tube drainage was significantly shorter for patients in group 2 (median two days) than for those in group 1 (median seven days).

Conclusions - The duration of chest tube drainage before sclerotherapy for malignant pleural effusions need not be influenced by the amount of fluid drained daily but by radiographic evidence of fluid evacuation and lung re-expansion. Shorter duration of drainage will reduce the length of hospital stay without sacrificing the efficacy of pleurodesis.
\end{abstract}

(Thorax 1994;49:23-25)

Malignant pleural effusions are associated with a poor prognosis and often cause distressing symptoms such as dyspnoea and cough. Although the underlying malignant lesion is usually incurable, evacuation of the effusion can provide considerable relief of symptoms. Such palliative treatment is commonly accomplished with tube thoracostomy drainage and the instillation of a sclerosing agent to induce a chemical pleuritis and obliterate the pleural space. Apposition of the visceral and parietal pleura before instillation of the sclerosing agent is necessary to achieve successful pleurodesis, ${ }^{12}$ but it is not clear what the optimal duration of tube thoracostomy drainage should be before and after instillation. Several studies have examined the efficacy of different sclerosing agents such as tetracycline, ${ }^{3-16}$ talc, ${ }^{17-23}$ quinacrine, ${ }^{624-29}$ and bleomycin. ${ }^{14162330-33}$ Some authors ${ }^{3435}$ have stated that the daily amount of fluid drained should be minimal - that is, less than $150 \mathrm{ml} /$ day before instillation of sclerosant, and some $e^{1636}$ have used this criterion for their study protocol. We found no data to support or refute this practice. We prospectively compared the efficacy of a protocol in which tetracycline was instilled when fluid drainage was less than $150 \mathrm{ml} /$ day with a short term drainage protocol in which tetracycline was instilled within 24 hours of insertion of the chest tube, provided there was radiological evidence of full lung re-expansion, irrespective of the amount of fluid draining.

\section{Methods}

DESIGN OF STUDY

This study was prospective and randomised; tetracycline was used because of its proven efficacy, good safety record, and low cost. ${ }^{3-16}$ The protocol was approved by the Research Committee/Institutional Review Board of the Lahey Clinic Medical Center.

\section{Eligibility}

Patients eligible for the study were those with a moderate to large malignant pleural effusion, proved by cytological examination or pleural biopsy, causing respiratory symptoms, and an expected survival of at least one month with a Karnofsky score $^{37}$ of at least $40 \%$ (disabled, requires special care and assistance). Patients were excluded if a previous chemical pleurodesis had been undertaken on the same effusion, or if ipsilateral atelectasis due to complete airway obstruction by endobronchial tumour was present.

\section{Treatment}

After giving informed consent patients were randomly assigned by computer to one of two 
Table 1 Demographic and primary disease characteristics

\begin{tabular}{lll}
\hline Characteristics & $\begin{array}{l}\text { Group 1 standard protocol } \\
(n=15)\end{array}$ & $\begin{array}{l}\text { Group 2 short term protocol } \\
(n=10)\end{array}$ \\
\hline Median (range) age (years) & $67 \cdot 5(41-81)$ & $70 \cdot 5(43-79)$ \\
Sex & 5 & 4 \\
$\quad$ Male & 10 & 6 \\
$\quad$ Female & 5 & 3 \\
Primary site of tumour & 5 & 6 \\
$\quad$ Breast & 0 & 1 \\
Lung & 3 & 0 \\
Prostate & 1 & 0 \\
Ovarian & 1 & 0 \\
$\quad$ Rectal & & \\
Unknown & & \\
\hline
\end{tabular}

groups. Patients in group 1 (standard protocol described by $\mathrm{Sahn}^{34}$ ) underwent tube thoracostomy suction drainage until re-expansion of the lung and until the amount of fluid drained was less than $150 \mathrm{ml} /$ day. Tetracycline $(1.5 \mathrm{~g}$ diluted in $100-150 \mathrm{ml}$ normal saline solution plus $20 \mathrm{ml} 1 \%$ lignocaine) was then instilled intrapleurally. The chest tube was removed when the amount of fluid drained after instillation was less than $150 \mathrm{ml} /$ day. Patients in group 2 (short term protocol) also had tube thoracostomy suction drainage, but the tetracycline $(1.5 \mathrm{~g}$ diluted in the same manner) was instilled as soon as full re-expansion of the lung was radiologically documented, which was usually within 24 hours. The chest tube was removed the day after instillation of tetracycline. Other aspects of the pleurodesis technique were similar in the two groups. For pleural drainage a 28French intercostal drainage catheter was inserted by the standard technique. After instillation of the tetracycline the tube was clamped and the position of the patient was rotated by the method described by Wallach. ${ }^{48}$ The tube was unclamped and suction drainage was resumed until the chest tube was removed.

A follow up chest radiograph was obtained after 30 days to determine the response to sclerotherapy. Subsequent follow up was provided by the patient's primary care physician.

\section{STATISTICAL ANALYSIS}

The two groups were compared with respect to demographic characteristics, site of primary tumour, duration of chest tube drainage, response to sclerotherapy, length of follow up study, and patient outcome. The response to sclerotherapy was determined by criteria described by Hausheer and Yarbo. ${ }^{35} \mathrm{~A}$ response was defined as having no fluid reaccumulation for at least one month as determined by chest

Table 2 Duration of chest tube drainage, response to sclerotherapy, length of follow up, and eventual patient outcome

\begin{tabular}{|c|c|c|c|}
\hline & $\begin{array}{l}\text { Group } 1 \text { standard } \\
\text { protocol }(n=15)\end{array}$ & $\begin{array}{l}\text { Group } 2 \text { short term } \\
\text { protocol }(n=9)^{*}\end{array}$ & $p$ \\
\hline $\begin{array}{l}\text { Median (range) duration of chest tube } \\
\text { drainage (days) }\end{array}$ & $7 \cdot 0(3-19)$ & $2 \cdot 0(2-9)$ & $<0.01$ \\
\hline $\begin{array}{l}\text { Response to sclerotherapy } \\
\text { Response } \\
\text { Non-response }\end{array}$ & $12(80 \%)$ & $7(78 \%)$ & NS \\
\hline $\begin{array}{l}\text { Median (range) length of follow up } \\
\text { (months) }\end{array}$ & $3 \cdot 0(1-26)$ & $1.0(1-9)$ & NS \\
\hline $\begin{array}{l}\text { Patient outcome } \\
\text { Alive } \\
\text { Dead }\end{array}$ & $\begin{array}{r}2 \\
13\end{array}$ & $\begin{array}{l}0 \\
9\end{array}$ & NS \\
\hline
\end{tabular}

* Data were incomplete in one patient. radiography, or no further requirement for fluid drainage within one month of treatment, or both. Non-response was defined as recurrence of greater than $50 \%$ of the original volume of effusion, or the requirement for fluid drainage within one month of treatment.

Continuous variables were analysed with the Mann-Whitney test. Contingency tables were analysed by Miettinen's modification of the Fisher exact test. Statistical significance of differences between distributions were analysed by the Tarone-Ware method. ${ }^{39}$ Probabilities are two-tailed with $\mathrm{p}<0.05$ being regarded as significant.

\section{Results}

Between May 1989 and August 199125 patients entered the study. Fifteen were randomly assigned to group 1 (standard protocol) and 10 to group 2 (short term protocol). The asymmetry between the size of the two groups was a result of the randomisation process. The demographic and primary disease characteristics are summarised in table 1 . No significant difference existed between the two groups with regard to age or sex distribution. The frequency of carcinoma of the breast or lung, the most common primary tumour sites, was similar for both groups.

The data on duration of chest tube drainage, response to sclerotherapy, length of follow up study, and patient outcome are summarised in table 2. As expected, the duration of chest tube drainage was significantly shorter for patients in group 2 (median two days) than for those in group 1 (median seven days). Two patients in group 2 required a relatively long period of drainage; one had slow re-expansion of the lung because of partial airway obstruction by tumour, and one had a prolonged bronchopleural fistula as a result of carcinoma of the lung.

The response to sclerotherapy was similar in the two groups, both having about an $80 \%$ response rate. The two patients in group 2 whose treatment failed had subsequent tube thoracostomy drainage and instillation of tetracycline by the standard protocol. Repeated attempts at sclerotherapy failed in both patients.

\section{Discussion}

Despite the poor prognosis associated with malignant pleural effusions, ${ }^{40-42}$ investigation into palliative treatment has been extensive. Treatments have included repeated thoracentesis, ${ }^{43}$ tube thoracostomy alone, ${ }^{4344}$ pleurectomy, ${ }^{434546}$ and placement of a pleuroperitoneal shunt, ${ }^{478}$ but the most commonly used method has been closed tube thoracostomy with instillation of a sclerosing agent. Much research has focused on the efficacy of sclerosing agents ${ }^{3-1825-28}$ but not on the duration of chest tube drainage required.

With the use of tetracycline as the sclerosing agent, no difference in efficacy was found whether we waited until the daily chest tube drainage was less than $150 \mathrm{ml} /$ day, as recommended by some authors, ${ }^{1634-36}$ or whether 
tetracycline was instilled as soon as the chest radiograph showed lung re-expansion which was usually within 24 hours. Both groups had an $80 \%$ response rate to tetracycline sclerotherapy, similar to published results. ${ }^{3-16}$ The duration of chest tube drainage, however, differed greatly. The median duration for patients in group 1 (seven days) was significantly longer than that for patients in group 2 (two days).

Two studies have been reported in which the authors stated that the duration of pleural drainage before instillation of the sclerosing agent was less than 24 hours; both reported successful pleurodesis. ${ }^{643}$ One study ${ }^{15}$ used intrapleural suction "until roentgenograms confirmed complete evacuation of the pleural space and complete lung expansion" before successful tetracycline pleurodesis, but did not report the duration of drainage. McAlpine $e t$ $a l^{49}$ surveyed chest physicians in the United Kingdom and found that "those using intercostal tube drainage tended to remove the drain either immediately or within 24 hours". They found that only $13 \%$ of respiratory physicians and $23 \%$ of thoracic surgeons varied the duration of drainage according to the volume of fluid drained-each day. Our study is the first to show in a prospective randomised trial that short term drainage before sclerotherapy is, indeed, effective.

We feel that, regardless of the sclerosing agent used, the duration of chest tube drainage need not be guided by the amount of fluid drained but by radiological evidence of fluid evacuation and lung re-expansion. This can result in a shorter duration of drainage, thus reducing the number of days in hospital and improving patient comfort without sacrificing efficacy of pleurodesis.

1 Malden LT, Tattersall MHN. Malignant effusions. $Q \mathcal{F}$ Med 1986;58:221-39.

2 Tattersall MHN, Boyer MJ. Management of malignant pleural effusions. Thorax 1990;45:81-2.

3 Rubinson RM, Bolooki H. Intrapleural tetracycline for control of malignant pleural effusion: a preliminary report. South Med F 1972;65:847-9.

4 Wallach HW. Intrapleural tetracycline for malignant pleural effusions. Chest 1975;68:510-2.

5 Sarma PR, Moore MR. Approach to the management of pleural effusion in malignancy. South Med $\mathcal{F} 1978 ; 71: 133-6$.

Bayly TC, Kisner DL, Sybert A, MacDonald JS, Tsou E, Bayly TC, Kisner DL, Sybert A, MacDonald JS, Tsou E,
Schein PS. Tetracycline and quinacrine in the control of malignant pleural effusions: a randomized trial. Cancer malignant pleural

7 O'Neill W, Spurr C, Moss H, Richards R, White D, Cooper MR. A prospective study of chest tube drainage and tetracycline sclerosis versus chest tube drainage alone in the treatment of malignant pleural effusions (Abstract). Proc AACR and ASCO 1980;21:349.

8 Gupta N, Opfell RW, Padova J, Margileta D, Soudjian J. Intrapleural bleomycin versus tetracycline for control of malignant pleural effusion: a randomized study (Abstract). Proc AACR and ASCO 1980;21:366.

9 Zaloznik AJ, Oswald SG, Langin M. Intrapleural tetracycline in malignant pleural effusions: a randomized study. Cancer 1983;51:752-5.

10 Leahy BC, Honeybourne D, Brear SG, Carroll KB, Thatcher N, Stretton TB. Treatment of malignant pleural effusions with intrapleural Corynebacterium parpleural effusions with intrapleural Corynebacterium

11 Fentiman IS, Rubens RD, Hayward JL. A comparison of intracavitary talc and tetracycline for the control of pleural effusions secondary to breast cancer. Eur $\mathcal{F}$ Cancer Clin Oncol 1986:22:1079-81.

12 Kefford RF, Woods RL, Fox RM, Tattersall MHN. Intracavitary adriamycin, nitrogen mustard and tetracycline in the control of malignant effusions. A randomised study Med f Aust 1986;2:447-8.

13 Gravelyn TR, Michelson MK, Gross BH, Sitrin RG Tetracycline pleurodesis for malignant pleural effusions: a 10-year retrospective study. Cancer 1987;59:1973-7.

14 Kessinger A, Wigton RS. Intracavitary bleomycin and tetracycline in the management of malignant pleural effusions: a randomized study. F Surg Oncol 1987;36:81-3. 15 Sherman S, Grady KJ, Seidman JC. Clinical experience with tetracycline pleurodesis of malignant pleural effusions. South Med $\mathcal{F} 1987 ; 80: 716-9$.

16 Ruckdeschel JC, Moores D, Lee JY, Einhorn LH, Mandelbaum I, Koeller J, et al. Intrapleural therapy for malignant pleural effusions: a randomized comparison of bleomycin and tetracycline. Chest 1991;100:1528-35.

17 Haupt GJ, Camishion RC, Templeton JY III, Gibbon JH Jr. Treatment of malignant pleural effusion by talc poudrage. $\mathcal{f} A M A$ 1960;172:918-21.

18 Camishion RC, Gibbon JH, Nealon TF. Talc poudrage in the treatment of pleural effusion due to cancer. Surg Clin North Am 1962;42:1521-6.

19 Starkey GW. Recurrent malignant pleural effusions. $N$ Engl f Med 1964;270:436-8.

20 Pearson FG, MacGregor DC. Talc poudrage for malignant pleural effusion. $\mathcal{F}$ Thorac Cardiovasc Surg 1966;51:732-8.

21 Adler RH, Rappole BW. Recurrent malignant pleural ef fusions and talc powder aerosol treatment. Surgery $1967 ; 62: 1000-6$.

22 Adler RH, Sayek I. Treatment of malignant pleural effusion: a method using tube thoracostomy and talc. $A n n$ Thorac Surg 1976;22:8-16.

23 Hamed H, Fentiman IS, Chaudary MA, Rubens RD. Comparison of intracavitary bleomycin and talc for conComparison of intracavitary bleomycin and talc for con-
trol of pleural effusions secondary to carcinoma of the trol of pleural effusions secondary
breast. $B r \mathcal{F}$ Surg 1989;76:1265-7.

24 Gellhorn A, Zaidenweber J. Ultmann J, Hirschberg E. The use of Atabrine (quinacrine) in the control of recurrent neoplastic effusions: a preliminary report. Dis Chest 1961;39:165-76.

25 Ultmann JE, Gellhorn A, Osnos M, Hirschberg E. The effect of quinacrine on neoplastic effusions and certain of their enzymes. Cancer 1963;16:283-8.

26 Rochlin DB, Smart CR, Wagner DE, Silva ARM. The control of recurrent malignant effusions using quinacrine hydrochloride. Surg Gynecol Obstet 1964;118:991-4.

27 Dollinger MR, Krakoff IH, Karnofsky DA. Quinacrine (Atabrine) in the treatment of neoplastic effusions. Ann Intern Med 1967;66:249-57.

28 Hickman JA, Jones MC. Treatment of neoplastic pleural effusions with local instillation of quinacrine (mepacrine) effusions with local instillation of quin
hydrochloride. Thorax 1970;25:226-9.

29 Taylor SA, Hooton NS, MacArthur AM. Quinacrine in the management of malignant pleural effusion. Br f Surg 1977;64:52-3.

30 Paladine $\mathbb{W}$, Cunningham TJ, Sponzo R, Donavan M, Olson $\mathrm{K}$, Horton J. Intracavitary bleomycin in the managemen of malignant effusions. Cancer 1976;38:1903-8.

31 Bitran JD, Brown C, Desser RK, Kozloff MF, Shapiro C Billings AA. Intracavitary bleomycin for the control of malignant effusions. I Surg Oncol 1981;16:273-7.

32 Ostrowski MJ. An assessment of the long-term results of controlling the reaccumulation of malignant effusions using intracavity bleomycin. Cancer 1986;57:721-7.

33 Ostrowski MJ, Priestman TJ, Houston RF, Martin WMC A randomized trial of intracavitary bleomycin and CorA randomized trial of intracavitary bleomycin and Corynebacterium parvum in the control of malig
effusions. Radiother Oncol 1989;14:19-26.

34 Sahn SA. Pleural effusion in lung cancer. Clin Chest Med 1982;3:443-52.

35 Hausheer FH, Yarbo JW. Diagnosis and treatment of malignant pleural effusion. Semin Oncol 1985;12:54-75.

36 Walsh FW, Alberts M, Solomon DA, Goldman AL. Malig nant pleural effusions: pleurodesis using a small-bore percutaneous catheter. South Med f 1989;82:963-72.

37 Karnofsky DA. Cited by Haskell CM, ed. Cancer treatment. 2nd edn. Philadelphia: Saunders, 1985:190.

38 Wallach HW. Intrapleural therapy with tetracycline and lidocaine for malignant pleural effusions (Letter). Chest 1978;73:246.

39 Tarone RE, Ware J. On distribution-free tests for equality of survival distributions. Biometrika 1977;64:156-60.

40 Light RW. Malignant pleural effusions. In: Light RW, ed Pleural diseases. 2nd edn. Philadelphia: Lea and Febiger, 1990:97-115.

41 Fentiman IS. Diagnosis and treatment of malignant pleural effusions. Cancer Treat Rev 1987;14:107-18.

42 Chernow B, Sahn SA. Carcinomatous involvement of the pleura: an analysis of 96 patients. Am f Med 1977;63:695702 .

43 Anderson CB, Philpott GW, Ferguson TB. The treatment of malignant pleural effusions. Cancer 1974;33:916-22.

44 Lambert CJ, Shah HH, Urschel HC Jr, Paulson DL. The treatment of malignant pleural effusions by closed trocar treatme drainage. Ann Thorac Surg 1967;3:1-5.

45 Jensik R, Cagle JE, Milloy F, Perlia C, Taylor S, Kofman $S$, et al. Pleurectomy in the treatment of pleural effusion
due to metastatic malignancy. $\mathcal{F}$ Thorac Cardiovasc Surg due to metastatic

46 Martini N, Bains MS, Beattie EJ Jr. Indications for pleurectomy in malignant effusion. Cancer 1975;35:734-8

47 Little AG, Kadowski MH, Ferguson MK, Staszek VM, Skinner DB. Pleuro-peritoneal shunting: alternative the apy for pleural effusions. Ann Surg 1988;208:443-50.

48 Tsang V, Fernando HG, Goldstraw P. Pleuro-peritoneal shunting for recurrent malignant pleural effusions. Thorax 1990;45:369-72.

49 McAlpine LG, Hulks G, Thomson NC. Management of recurrent malignant pleural effusion in the United King dom: survey of clinical practice. Thorax 1990;45:699-701. 